\title{
4
}

\section{TESTIMONIOS ORALES: REPRESENTACIONES NARRATIVAS EN LA CONSTRUCCIÓN DEL SIGNIFICADO}

\author{
Fabiana Alonso (coord.), \\ Luis Escobar, Luciano Montenegro, \\ Valeria Pini
}

DENOMINACIÓN DEL TRAYECTO

< LA ENTREVISTA COMO DISCURSO NARRATIVO SINGULAR >

No sé qué es lo que consigue atraerme en esa historia difusa, lejana, erizada de improbabilidades. No sé por qué pido hablar con ese hombre, por qué estoy hablando con Juan Carlos Livraga. (...) Livraga me cuenta su historia increíble; la creo en el acto. Así nace aquella investigación, este libro. 
En las últimas décadas hemos asistido al desarrollo de perspectivas centradas en abordajes narrativos para dar cuenta de la manifestación de la subjetividad en y por el lenguaje y del modo en que los individuos le asignan significación a sus experiencias. Temporalidad, selectividad, interpretación, construcción del sentido son algunos de los modos narrativos para hacer inteligibles las experiencias evocadas.

En tanto que discurso narrativo singular, la entrevista puede caracterizarse como una situación comunicativa regida por un intercambio dialógico, de recorrido azaroso. Si bien el diálogo se presenta como un lazo de proximidad, al mismo tiempo oculta normativas que rigen las posiciones no intercambiables de entrevistador y entrevistado, los temas y los recorridos autorizados, los límites y hasta las posibles infracciones.

\section{RESUMEN E IMPACTO DE LA PROPUESTA}

Este trayecto investigativo se propone realizar aportes en relación con la entrevista como construcción narrativa y como producto no espontáneo, posibilitado por la relación que se establece entre dos interlocutores (uno de ellos, un investigador), lo cual habilita para pensar la entrevista como narrativa compartida (Huberman, 1998) o bien como invención dialógica (Arfuch, 1995).

El abordaje de la entrevista como construcción narrativa se hará sin perder de vista que esta forma particular de dar cuenta de la lucha por fijar sentidos (Mumby, 1997) consiste, en términos de Bourdieu (2000), en visiones y perspectivas que los agentes producen en sus luchas prácticas dentro de un campo. Esto implica la necesidad de articular las puestas en sentido con las prácticas sociales.

Por otro lado, requiere problematizar cuestiones de orden teórico y metodológico referidas a la producción y al análisis de los testimonios orales como vía de acceso a aspectos difíciles de hallar en otro tipo de fuentes. 


\subsection{LA PROBLEMÁTICA EN CUESTIÓN}

1.1.1. La entrevista pone de manifiesto los dos universos existenciales: el privado y el público. En ella se da cita una pluralidad de voces que remiten a la trama sociocultural desde la que hablan los sujetos. En tanto que los relatos personales remiten a experiencias sociales, estamos en presencia de una trama polifónica que desdibuja la ilusión de que el individuo que habla es fuente absoluta de su palabra (Arfuch, 1995).

1.1.2. Los testimonios orales son construcciones, interpretaciones acerca del pasado (Schwarzstein, 2001). En este sentido, las evocaciones no están disociadas del presente de la enunciación, lo que introduce la problemática de la temporalidad.

"La narración inscribe la experiencia en una temporalidad que no es la de su acontecer (amenazado desde su mismo comienzo por el paso del tiempo y lo irrepetible), sino la de su recuerdo. La narración también funda una temporalidad, que en cada repetición y en cada variante volvería a actualizarse" (Sarlo, 2005: 29).

Los cambios operados en el contexto político y las variaciones en las posiciones de los entrevistados inciden en las evaluaciones de sus acciones. Los individuos pueden revisar sus conductas a la luz de nueva información. Las reflexiones pueden ser producto del diálogo entre las experiencias pasadas y el contexto presente en que se recuerda, debido a que en las perspectivas de recuperación de los recuerdos están implícitas las circunstancias cambiantes en las que los individuos le asignan sentido a sus prácticas.

“Ubicar temporalmente a la memoria significa hacer referencia 'al espacio de la experiencia' en un presente. El recuerdo del pasado está incorporado, pero de manera dinámica, porque las experiencias incorporadas pueden modificarse en el tiempo" (Jelin, 2004: 103). 
1.1.3. Los sucesos traumáticos repercuten en la esfera de la subjetividad y pueden manifestarse en omisiones, olvidos e incluso distorsiones. Es importante considerar que estas últimas también son construcciones del significado (Portelli, 2005).

“El proceso de olvidar y recordar puede tornarse más complejo y las historias pueden contener mayor cantidad de elementos imaginados, fragmentados y desarticulados" (Schwarzstein, 2001: XXIII).

1.1.4. La construcción del universo testimonial plantea el problema del control del volumen de habla cuando se trata de una época de sobrevivientes: por qué considerar representativos determinados testimonios; cómo construir un corpus válido frente a una posible gran cantidad de testimonios (Raiter, 1999). Cuando se trata de una temática que supone la existencia de distintas versiones sobre lo ocurrido, el universo testimonial debe ser lo suficientemente abarcativo. Al respecto, es válida la observación de Jelin acerca de que es casi imposible hallar una única versión de lo acontecido, de ahí que sea pertinente hablar de memorias (en plural). Al igual que la realidad social, lo que llamamos memoria está atravesado por tensiones y es un espacio de lucha acerca del sentido del pasado.

1.1.5. Dado que el contexto de emisión condiciona el testimonio, es preciso tener en cuenta tanto las propiedades del discurso como otros elementos presentes en la comunicación, que también contribuyen a la significación. En este sentido, es conveniente considerar el rol del entrevistador, si varía el modo de tratamiento de un mismo tema según los entrevistados, cómo éstos se ven a sí mismos, cómo interpretan los aspectos del evento comunicativo que les resultan relevantes (Van Dijk, 1998). Asimismo, se podrá tener en cuenta todo lo que funciona a espaldas de los interlocutores; esto es, las variables a considerar para analizar la forma que adopta la interacción lingüística: género, grado de escolaridad, origen social, residencia, etc. (Bourdieu, 1999).

1.1.6. La importancia significante de la narración radica en el uso que de ella hacen los hablantes. Dado que los significados son contextuales y situados, 
atender a las formas del lenguaje en uso puede dar cuenta de diferencias semánticas, efectos ideológicos, distorsiones u ocultamiento de otras perspectivas, legitimación de un punto de vista en detrimento de otro (Van Dijk, 1998), así como las formas en que dialogan entre sí diferentes discursos (Arfuch, 1995).

1.1.7. Los testimonios orales pueden constituirse en fuentes relevantes para el abordaje de la historia reciente, lo que no obstaculiza la posibilidad de un cruce de los mismos con otro tipo de fuentes. No obstante, al decir de Portelli (2005), se trata de uno de los modos de interpretarlos, no de verificarlos.

1.1.8. Las consideraciones precedentes imponen la necesidad de recurrir a presupuestos teóricos y metodológicos para el análisis de testimonios orales y no tomar como dados los significados presentes en los mismos (Raiter, 1999). En relación con esta cuestión, Sarlo (2005) señala la necesidad de que en el trabajo con relatos de la memoria haya rupturas con el sentido común, extrañamientos y distanciamientos posibilitados por principios explicativos y por remisiones teóricas.

\section{ALGUNOS ANTECEDENTES SOBRE EL TEMA}

La utilización de testimonios orales es de larga data en la investigación social. En los años '20, la Escuela de Chicago abrió el camino de lo que hoy se conoce como investigación cualitativa a partir de la producción de relatos o historias de vida. Luego de la Segunda Guerra Mundial, en la Universidad de Columbia comenzó a organizarse un archivo de entrevistas a personalidades políticas. En Inglaterra, a fines de los años '60, empezó a desarrollarse lo que se conoce como historia desde abajo (en sus comienzos, alejada del campo académico), cuyo propósito era construir la historia de los sectores oprimidos: trabajadores, mujeres, grupos marginales...

La producción de testimonios orales cobró importancia en diversos campos de investigación: antropología, sociología, educación, historia. En este sentido, adquirieron relevancia las narrativas biográficas y las historias de vida como objeto de investigación y como metodología. 
En América latina, a partir de la transición a la democracia, en los años '80, luego de las dictaduras militares, las ciencias sociales comenzaron a configurar un nuevo campo de preocupación centrado en las memorias de la violencia política y la represión (Jelin, 2004).

En relación con la producción de testimonios, desde el campo de la historia oral se plantea que su importancia radica más en el valor -en tanto que pueden dar cuenta de aspectos ausentes en otro tipo de fuentes-que en la veracidad. Los desarrollos más recientes señalan que los argumentos de sus principales críticos, a saber: la subjetividad, los problemas de fiabilidad (debido a las fallas de la memoria), el énfasis en lo particular, deben ser planteados no en términos de debilidades sino como elementos que requieren ser resituados y analizados desde registros específicos (Aguila y Viano, 2002).

En el campo historiográfico argentino, a partir de la década del '80 comenzaron a plantearse discusiones sobre problemas y cuestiones metodológicas respecto de la historia oral. En los últimos años ha habido un cambio de posición ante el análisis del testimonio oral en relación con la construcción del discurso del investigador. Schwarzstein (2001) señala que los testimonios orales no son un simple registro de hechos del pasado y tampoco están llamados a llenar los vacíos dejados por otro tipo de documentos. Se trata de productos culturales complejos que incluyen interrelaciones entre memorias privadas y públicas, entre experiencias pasadas y situaciones presentes y entre representaciones del pasado y del presente.

\section{AVANCES EN LA FUNDAMENTACIÓN TEÓRICA}

La consideración de la entrevista como constructo narrativo requiere examinar de manera crítica la dicotomía establecida en la ciencia moderna entre objetividad y subjetividad que, en la actualidad, se encuentra enraizada en diversas metodologías utilizadas en el ámbito de las ciencias sociales.

Como modo de conocimiento, el relato capta la riqueza y detalles de los significados en los asuntos humanos (motivaciones, sentimientos, deseos o propósitos) que no pueden ser expresados en definiciones, enunciados factuales 
o proposiciones abstractas, como aspira un razonamiento lógico-formal. La entrevista, desde esta perspectiva ligada al ideal positivista, es concebida como una fuente de información, plausible de verificación / aclaración / comprobación de un referente que se encuentra fuera del evento que la entrevista constituye, suponiendo la distancia entre el investigador y el objeto investigado. Mayor despersonalización produciría un incremento de la objetividad necesaria para que el conocimiento adquiera el carácter de cientificidad.

En la década del '70, el auge del giro lingüístico, paralelo a la puesta en cuestión del positivismo y de la pretensión de dar una explicación científica a las acciones humanas, posibilitó entender los fenómenos sociales como textos, cuyo valor y significado vienen dados por la interpretación que de ellas hacen los agentes. Desde esta perspectiva, una hermenéutica-narrativa permite la comprensión de la complejidad de las narraciones que los individuos elaboran acerca de los conflictos y los dilemas en sus vidas.

La investigación hermenéutica se dirige a dar sentido y a comprender (frente a la explicación por relaciones causales) la experiencia vivida y narrada. Desde esta perspectiva, la narrativa no es sólo una metodología sino una forma de construir la realidad, por lo que la metodología se asienta en una ontología. La individualidad no puede explicarse únicamente por referentes universales que se encuentran fuera de la constitución del sujeto en un medio determinado. La subjetividad es una condición necesaria del conocimiento social.

La narrativa no sólo expresa importantes dimensiones de la experiencia vivida sino que, más radicalmente, media la propia experiencia y configura la construcción social de la realidad. El enfoque narrativo prioriza un yo dialógico relacionado con la sociedad, en el que la subjetividad es una construcción social intersubjetivamente conformada por el discurso que comunica. El juego de subjetividades en un proceso dialógico se convierte en un modo privilegiado de construir conocimiento.

En el marco de la filosofía alemana del lenguaje', Gadamer (1992) advierte

\footnotetext{
${ }^{1}$ La superación de la concepción tradicional del lenguaje como instrumento para la designación de entidades independientes del mismo o para la comunicación de pensamientos prelingüísticos, y el reconocimiento de que al lenguaje le corresponde un papel constitutivo en nuestra relación con el mundo, ha conformado el tránsito de la filosofía de la conciencia a la filosofía del lenguaje.
} 
que la sociedad humana vive en instituciones que aparecen determinadas por la autocomprensión interna de los individuos que forman la sociedad. No hay ninguna realidad social, con todas sus presiones reales, que no se exprese en una conciencia lingüísticamente articulada.

El enfoque hermenéutico concibe a la narrativa como la cualidad estructurada de la experiencia, entendida y vista como un relato. Como enfoque de investigación, la narrativa implica las pautas y las formas de construir sentido, a partir de acciones temporales personales, por medio de la descripción y análisis de los datos biográficos. Se trata de una particular reconstrucción de la experiencia que, mediante un proceso reflexivo, otorga significado a lo sucedido y vivido.

Narrativizar la vida en un autorrelato es, al decir de Ricoeur (1995), un medio de inventar el propio yo, de darle una identidad (narrativa). En su expresión superior (autobiografía) es también la elaboración del proyecto ético de lo que ha sido y será la vida. El sentido de una acción, lo que la hace inteligible, sólo podrá venir dado por la explicación narrativa del agente sobre las intenciones, motivos y propósitos que tiene para él a corto plazo y, más ampliamente, en el horizonte de su vida.

Este énfasis en la narrativa, que expresa el interés por volver a las experiencias significativas que encontramos en la vida diaria, no coarta la posibilidad del trabajo científico. En términos epistemológicos supondría que, si la explicación es el modo de dar cuenta de los fenómenos naturales estableciendo conexiones constantes entre sus elementos, la comprensión (desde el enfoque hermenéutico) sería el modo de dar cuenta de las acciones humanas, desde las intenciones que le confieren sentido. En palabras de Ricoeur, es pertinente plantear las investigaciones de las ciencias sociales en términos dialécticos: la necesaria mediación de la comprensión por la explicación y, alternativamente, de la segunda a la primera.

\section{ORIENTACIONES Y PRECISIONES METODOLÓGICAS}

Respecto de la metodología a seguir, el trayecto presenta una estructura general que se re-adecuará o modificará de acuerdo con los avances y desarrollos de 
las investigaciones particulares realizadas dentro del mismo. No obstante, en sus tramos iniciales retoma, siguiendo a Thompson (1987), un enfoque hermenéutico en profundidad, con lo que se pretende un análisis de tres niveles en relación con nuestro objeto, la entrevista de investigación:

> Análisis sociohistórico

$>$ Análisis formal o discursivo

$>$ Interpretación

Estos tres niveles no son secuenciales, sino que constituyen un mismo proceso. El análisis sociohistórico refiere a que el objeto de investigación es producido y recibido en circunstancias sociohistóricas específicas y, por tal motivo, está atravesado por distintos dispositivos institucionales, tanto de poder como de dominación.

El análisis formal y discursivo comprende la explicación de los rasgos y las relaciones estructurales que puedan facilitar la movilización del significado a través del estudio de sus estructuras sintáctica y narrativa. En tal sentido, se tendrán como referencia los aportes del análisis crítico del discurso o lingüística crítica para dar cuenta de que no sólo lo dicho sino también lo no dicho en cualquier evento comunicativo resultan pertinentes y formativos en la instancia de significación de un mensaje. Por último, la interpretación constituye el momento en el cual se anudan los dos niveles anteriores, proyectando el posible significado y revelando su funcionalidad.

Este enfoque cualitativo permite superar el problema del olvido del referente, crítica realizada al giro lingüístico, y problematizar la operatividad del contexto, como así también facilitar el análisis de la ideología al proporcionar un acceso inicial a los procesos de reificación dentro del lenguaje. Intenta incluir, además, a los mismos investigadores ya que no están exentos de la problemática de la ideología, de allí la importancia de rescatar algunos supuestos del paradigma interpretativo, sobre todo la necesidad constante de una vigilancia epistemológica del trabajo científico.

El desarrollo cronológico del trayecto considerará una extensión de dieciocho meses, durante los cuales las distintas investigaciones individuales desarrollarán el entrecruzamiento de los niveles de análisis anteriormente descriptos. 


\section{Durante dicho período se llevará a cabo la delimitación definitiva de los distin- tos corpus ${ }^{2}$, los avances particulares y generales en el análisis de las entrevistas y las producciones finales. Las posibles modificaciones del trayecto, si bien incidirán sobre su curso, no transgredirán, en lo esencial, los lineamientos metodológicos aquí esbozados.}

2 Este trayecto comprende cuatro investigaciones particulares circunscriptas al ámbito santafesino; tres de ellas comparten el mismo marco temporal (décadas del '60 y del '70). La primera línea de investigación se propone la realización de entrevistas a militantes sindicales de la docencia de las siguientes organizaciones: Asociación del Magisterio, Asociación del Magisterio Católico y Sindicato Único de Trabajadores de la Educación de Santa Fe. En la primera etapa de la investigación se indagará en la construcción de identidades, en los esquemas prácticos a través de los cuales los entrevistados representan sus posicionamientos, estrategias y acciones, propios y de los demás, y en los diálogos entre los discursos pedagógicos y los discursos políticos. El segundo trabajo, centrado en entrevistas a miembros de la organización Montoneros, se propone abordar los modos en que los entrevistados construyen, interpretan y actualizan el pasado evocado, los problemas inherentes a la dimensión temporal y a la subjetividad en relación con las prácticas políticas. Las dos últimas propuestas se relacionan a partir de la investigación del campo religioso. Una de ellas abordará la radicalización católica a partir del Concilio Vaticano II e indagará, a partir de las entrevistas, en los cruces entre redes sociales, cultura religiosa, fe y praxis. La otra se abocará, desde la perspectiva de la historia del tiempo presente, al estudio de un nuevo movimiento dentro de la Iglesia católica: la renovación carismática. 


\section{REFERENCIAS BIBLIOGRÁFICAS ${ }^{3}$}

Águila, G. y Viano, C. (2002). "Las voces del conflicto: en defensa de la historia oral", en Godoy, C. [comp.] Historiografía y memoria colectiva. Tiempos y territorios. Buenos Aires: Miño y Dávila.

Arfuch, L. (1995). La entrevista, una invención dialógica. Barcelona: Paidós.

Bourdieu, P. (2000). Cosas dichas. Barcelona: Gedisa.

Bourdieu, P. (1999). Intelectuales, política y poder. Buenos Aires: Eudeba.

Bourdieu, P. (1997). Razones prácticas. Sobre la teoría de la acción. Barcelona: Anagrama.

Bourdieu, P. (1999). ¿Qué significa hablar? Economía de los intercambios lingüísticos. Madrid: Akal.

Bourdieu, P. (2000). Los usos sociales de la ciencia. Buenos Aires: Nueva Visión.

Bruner, J. (1988). Realidad mental, mundos posibles. Barcelona: Gedisa.

Bruner, J. (1997). La educación, puerta de la cultura. Madrid: Visor. Carrascoso, J.L. (2002). "De la Hermenéutica a la acción comunicativa. Entre la experiencia de la nada y la experiencia del Tú", en Logos. Anales del Seminario de Metafísica. Vol. 35. Universidad de Barcelona.

Foucault, M. (1992). El orden del discurso. Buenos Aires: Tusquets.

Gadamer, H.G. (1992). Verdad y método, II. Salamanca: Sígueme.

Huberman, M. (1998). "Trabajando con narrativas biográficas", en Mc. Ewan, H. y Egan, K. [comp.] La narrativa en la enseñanza, el aprendizaje y la investigación. Buenos Aires: Amorrortu.

Jelin, E. (2004). "Los derechos humanos y la memoria de la violencia política y la represión: la construcción de un campo nuevo en las ciencias sociales", en Estudios Sociales. Revista universitaria semestral. Año XIV, № 27, segundo semestre, Santa Fe: Universidad Nacional del Litoral.

Lafont, C. (1993) La razón como lenguaje. Una revisión del Giro lingüístico en la filosofía alemana del lenguaje. Madrid: Visor. 
Lulo, J. (2002). “La vía hermenéutica; las ciencias sociales entre la epistemología y la ontología", en Schuster, F. Filosofía y métodos de las ciencias sociales. Buenos Aires: Manantial.

Mumby, D. [comp.] (1997). Narrativa y control social. Perspectivas críticas. Buenos Aires: Amorrortu.

Portelli, A. (2005). "El uso de la entrevista en la historia oral", en Historia, memoria y pasado reciente. Anuario $\mathrm{N}^{\circ} 20$. Escuela de Historia. Facultad de Humanidades y Artes. Universidad Nacional de Rosario.

Raiter, A. (1995). Lenguaje en uso. Enfoque sociolingüístico. Buenos Aires: A Z.

Raiter, A. y otros (1999). Discurso y ciencia social. Buenos Aires: Eudeba.

Ricoeur, P. (1995). Tiempo y narración. I, II y III. Configuración del tiempo. Configuración del tiempo en el relato de ficción. El tiempo narrado. México: Siglo XXI.

Sarlo, B. (2005). Tiempo pasado. Cultura de la memoria y giro subjetivo. Una discusión. Buenos Aires: Siglo XXI.

Schwarzstein, D. (2001). Entre Franco y Perón. Memoria e identidad del exilio republicano español en Argentina. Barcelona: Crítica.

Thompson, J.B. (1986/87). "Lenguaje e ideología", en Revista Zona Abierta, 41/42, Madrid.

Van Dijk, T. (1998). Ideología. Una aproximación multidisciplinaria. Barcelona: Gedisa. 